\title{
Cost of managing complications resulting from type 2 diabetes
} mellitus in Canada

\author{
Judith A O'Brien*1, Amanda R Patrick ${ }^{1}$ and J Jaime Caro1,2
}

Address: ${ }^{1}$ Caro Research Institute, Concord, MA, U.S.A and ${ }^{2}$ Division of General Internal Medicine, Royal Victoria Hospital, McGill University, Montreal, P.Q., Canada

Email: Judith A O'Brien* - jobrien@caroresearch.com; Amanda R Patrick - apatrick@hsph.harvard.edu; J Jaime Caro - jcaro@caroresearch.com

* Corresponding author

Published: 2I March 2003

BMC Health Services Research 2003, 3:7

This article is available from: http://www.biomedcentral.com/I472-6963/3/7

(c) 2003 O'Brien et al; licensee BioMed Central Ltd. This is an Open Access article: verbatim copying and redistribution of this article are permitted in all media for any purpose, provided this notice is preserved along with the article's original URL.
Received: 21 November 2002

Accepted: 21 March 2003

\begin{abstract}
Background: Decision makers need to have Canadian-specific cost information in order to develop an accurate picture of diabetes management. The objective of this study is to estimate direct medical costs of managing complications of diabetes. Complication costs were estimated by applying unit costs to typical resource use profiles. For each complication, the event costs refer to those associated with the acute episode and subsequent care in the first year. State costs are the annual costs of continued management. Data were obtained from many Canadian sources, including the Ontario Case Cost Project, physician and laboratory fee schedules, formularies, reports, and literature. All costs are expressed in 2000 Canadian dollars.
\end{abstract}

Results: Major events (e.g., acute myocardial infarction: $\$ 18,635$ event cost; $\$ 1,193$ state cost), generate a greater financial burden than early stage complications (e.g., microalbuminuria: $\$ 62$ event cost; $\$ 10$ state cost). Yet, complications that are initially relatively low in cost (e.g., microalbuminuria) can progress to more costly advanced stages (e.g., end-stage renal disease, $\$ 63,045$ state cost).

Conclusions: Macrovascular and microvascular complication costs should be included in any economic analysis of diabetes. This paper provides Canadian-based cost information needed to inform critical decisions about spending limited health care dollars on emerging new therapies and public health initiatives.

\section{Background}

Diabetes mellitus is a chronic disorder that has been recognized by the Canadian government as a major public health problem with far reaching consequences not just for its adverse impact on the health of Canadians, but also for the economic burden it places on the health care system. In recognition of the seriousness of the problem, over 100 million dollars has been set aside to fund the Canadian Diabetes Strategy - a comprehensive national plan focusing on the prevention of diabetes through health promotion and education [1]. Targeting diabetes in this way is not surprising as it has been estimated that over 1 million Canadians are known to be afflicted with this condition, with $90 \%$ having type 2 diabetes [2]. Furthermore, it is acknowledged that this is likely an underestimation of the scope of the disease as up to 1 in 2 persons with diabetes do not know they have it [3].

The clinical consequences of diabetes can be life threatening and disabling. Diabetes is ranked as the seventh leading cause of death in Canada with at least 5,500 deaths per year attributed directly to the condition itself; however, 
this number rises dramatically to approximately 25,000 when deaths from diabetic complications are included [1]. Coronary heart disease is the leading cause of death in patients with diabetes [3].

There is an established connection between diabetes and both macrovascular and microvascular complications [46]. It has been reported that in Canada $21 \%$ of patients with diabetes have heart disease [7] and that $25 \%$ of all cardiac surgery can be attributed to diabetes. It is also the leading cause of both end-stage renal disease (ESRD) and non-traumatic lower extremity amputations (LEAs) in Canada, accounting for $32 \%$ and $50 \%$ of new cases, respectively $[8,9]$. Four hundred new cases of blindness can be attributed to diabetes each year, making diabetes the leading cause of new blindness in Canadian adults [10]. Many of the complications of diabetes are particularly debilitating to the patient, accompanied not only by a personal physical and emotional burden, but a significant economic one for the patient, family members, the nation as a whole and the health care system in particular. Health Canada has reported that twice as many patients with diabetes of working age reported disability days in a set period than their non-diabetic contemporaries [7].

In 1993, the economic burden of diabetes to Canada was estimated at $\$ 1.1$ billion annually [11]. It has been acknowledged that this is a gross underestimation as costs related to the complications of diabetes were not included [7]. A later projection of $\$ 9$ billion (US\$) annually, which included both direct and indirect costs was established [6]. This estimate was derived, however, based on published studies from the United States (US) and by making adjustments for differences in population sizes between the two countries. Given the sources for this estimate, it could be argued that it does not accurately reflect the cost of diabetes for Canada. Yet, it is not uncommon to see USbased proxy costs in Canadian reports, as there is a marked lack of Canadian-specific cost information relating to diabetes and its complications in the literature.

Given the recent initiatives of the Canadian government to target diabetes at a national level, diabetes and its complications are clearly an ongoing concern for health care decision makers. To make informed decisions about diabetes-related care and new therapeutic interventions, such as emerging oral hypoglycemics, these decision makers need to have Canadian-specific cost information. Moreover, to ensure an accurate picture of the cost of managing diabetes the typical broad cost estimates are not useful because they do not distinguish among determinants of resource use and their time course and thus cannot help sort out the implications of changes in policy. For example, if a new drug is more expensive but reduces the frequency of hyperglycemia then its economic assessment must ad- dress costs at a more detailed level. Building on our previously published work on the Canadian costs of major macrovascular complications of diabetes [12], the aim of this paper is to provide key pieces of that complex economic puzzle. This paper presents updated Canadian-specific cost information for macrovascular complications and new information on microvascular complications. The complications included in the analysis were chosen based on those considered in published epidemiological and economic models of diabetes [13-15]. Data are presented in a comprehensive manner so that researchers can examine the cost per patient for each complication.

\section{Methods}

It must be noted that the cost estimates presented are not the total costs due to these complications for the Canadian diabetic population, but rather, the typical costs of key components in an episode of illness. Average per-patient total costs were estimated by applying unit costs to the likely course of treatment for each complication. The macrovascular complications considered in this analysis are acute myocardial infarction(AMI), angina pectoris, ischemic stroke, and transient ischemic attacks (TIA). Microvascular complications include various levels of nephropathy (i.e., microalbuminuria, gross proteinuria, ESRD), retinopathy (i.e., proliferative retinopathy, macular edema, blindness), symptomatic neuropathy, LEA, and foot ulcers. While LEA and foot ulcers have been considered as neuropathic microvascular complications in this analysis, there is also a macrovascular component to these complications. Hypoglycemia was also considered as an acute complication.

The methodology and format used for developing and presenting the cost estimates in this paper have been published in earlier papers addressing the same complications for the U.S., and major macrovascular costs in Canada $[12,16]$. The cost of each complication is reported separately for the "event" and for the subsequent "state". Event costs are those associated with resource use specific to the defining clinical event and include both acute care (initial management in an inpatient or outpatient setting) and event-related health care delivered subsequently in the first year. This care may include subacute inpatient care (i.e., rehabilitation units within an acute care hospital, rehabilitation hospitals, nursing home facilities), home health care, outpatient therapy, physician visits, day care and diagnostic and therapeutic procedures, depending on the complication addressed.

For many of the complications, the resulting management costs persist after the event because it has placed the patient in a new health state. For these complications it is important to consider the ongoing, or state, costs. The state costs presented in this paper refer to the annual 
Table I: ICD-9 codes used to identify inpatient groups. Diagnosis codes refer only to principal diagnosis or identifying procedure code

\begin{tabular}{lc}
\hline Complication & ICD-9 code \\
\hline AMI & $410.00-410.9 I$ \\
Angina & $4 \mid 3.0-413.9,4 I I . I$ \\
Ischemic Stroke & $433 . x I^{*}, 434 . x \times$ II, 436 \\
TIA & 435.9 \\
Ist LEA & $84.10-84.17$ \\
$2^{\text {nd }}$ LEA & $84.10-84.17$ \\
Diabetic Foot Ulcer & 707.1 \\
Hypoglycemia & $250.8 \times \$$
\end{tabular}

$($ ICD-9 = International Classification of Diseases, 9 th revision, AMI = acute myocardial infarction, TIA = transient ischemic attack, LEA = lower extremity amputation) $*_{x}$ indicates that all fourth digits related to this root code were included. $\mid x x$ indicates that all fourth and fifth digits related to this root code were included. $\S x$ indicates that all fifth digits related to this code were included.

management costs for years subsequent to the event year and reflect the typical utilization of health care services for the ongoing management of the given health state. Some of the complications (i.e., foot ulcers, hypoglycemia) however, may not have a permanent effect on a person's health state, as they are potentially reversible and thus episodic events that can occur more than once. Given that these conditions are limited in duration, only event costs are applicable and no state costs are reported.

All event and state costs reported in this paper are incremental to any recommended measures that take place as part of routine diabetes management, the costs of which are not included in this analysis.

\section{Cost Sources}

As no one data source was available from which to abstract resource use and cost-relevant data for this analysis, it was necessary to gather information from a variety of pertinent sources. Acute inpatient resource use and costs were derived primarily from the 1994-95 and 1995-96 Ontario Case Cost Project (OCCP) databases $[17,18]$. OCCP is a joint program of the Ontario Ministry of Health and the Ontario Hospital Association. It was initiated for the purpose of developing information based on case cost data for funding and hospital management purposes. Patients with the analysis-relevant complications were identified by a principal diagnosis code (Table 1) using International Classification of Diseases (ICD-9) codes [19]. Where possible, only patients with a secondary diagnosis code of diabetes were included in the analysis. For example, diabetic patients admitted primarily for AMI were identified by a principal diagnosis code of AMI (ICD9: 410.0-410.9) and a secondary diagnosis code documenting diabetes (ICD9:250.00-250.93). When the number of diabetic patients with a specific complication was insufficient to perform a reliable analysis, the population was expanded to include non-diabetic patients with that complication, as the focus of the analysis was to develop the cost of managing the complication and not diabetes. Additional cost-related information based on Case Mix Groupings (CMGs) for 1996 [20] was also reviewed and used when necessary to supplement the ICD9-based data. Acute care hospital cost estimates include, all accommodation (e.g., routine and special care units), ancillary services (e.g., pharmacy, laboratory), emergency room, operating room, diagnostic and therapeutic procedures, and physician costs. As physician costs are not included in the OCCP data nor reported in the literature in sufficient detail, it was necessary to develop the corresponding resource use profiles. The OCCP data and the medical literature were used to develop these based on length of stay (LOS), physician service data, and the use of resource intensive services such as the emergency room, surgical procedures such as LEA, special care units, and consultations.

Recognizing the need for continuation of health care services upon discharge, post-acute care resource use profiles were developed. To develop these profiles, data from OCCP on disposition at discharge were supplemented with information from the Alberta Ambulatory Care Costing project [21], the Canadian Diabetes Association [6], the Heart Disease and Stroke Foundation of Canada $[22,23]$, Health Canada [23-25], Canadian clinical practice guidelines [26-28], other government and institutional reports [29-33], provider survey data on day care and cardiac rehabilitation, and peer-reviewed literature [34-38]. In order to maintain consistency with the OCCP data, Ontario provincial fee schedules and formulary [3941] were used as unit cost sources for physician-related care, laboratory tests, and medications. Additional references used for specific complications are noted within the appropriate sections of this paper.

Reimbursement for health care in Canada is largely provincial rather than federal; therefore in order to derive 
Table 2: Typical event (first year) and state costs (subsequent annual cost) for complications (2000 \$Canadian)

\begin{tabular}{lll}
\hline Complication & Event Cost & State Cost \\
\hline Cardiovascular Disease & & 1,193 \\
Acute myocardial infarction & 18,635 & 1,485 \\
Angina & 3,183 & \\
Cerebrovascular Disease & & 8,769 \\
Stroke & 33,256 & 73 \\
Transient Ischemic Attack & 3,262 & 10 \\
Nephropathy & & 18 \\
Microalbuminuria & 62 & 63,045 \\
Gross proteinuria & 54 & - \\
End Stage Renal Disease & - & 40 \\
Retinopathy & - & 40 \\
Macular edema (ME) with photocoagulation & 423 & 40 \\
Proliferative retinopathy with photocoagulation & 379 & 2,111 \\
ME and proliferative retinopathy with photocoagulation & 495 & \\
Blindness & - & - \\
Neuropathy & & 1,020 \\
Symptomatic neuropathy & 148 & - \\
Lower extremity amputation (LEA) I & 24,583 & \\
LEA 2 & 26,077 & - \\
Episodic & 2,183 & - \\
Foot ulcer & 1111 & \\
Hypoglycemia & & \\
\hline
\end{tabular}

"national" costs, it was necessary to adjust provincial data. Published health and personal care data from Statistics Canada [42] were used to derive a ratio between provincial and national healthcare costs by cost center for each province. Provincial unit costs were then adjusted using these ratios to derive the national equivalent.

There are several modalities of treatment for ESRD (e.g., hemodialysis, peritoneal dialysis, renal transplant). Annual costs of caring for patients on each of these were applied to the proportion of patients receiving that type of treatment to give a weighted average cost. While the distribution was taken from 1998 data, it was assumed that the ESRD population is in a steady state - that is, the patients leaving the ESRD populations and the patients entering the ESRD population during a given year have approximately the same modality distribution such that the overall distribution does not vary significantly from year to year. The distribution of treatment modalities for the 1998 Canadian ESRD population was obtained from the Canadian Institute for Health Information [43-45]. There is a definite and discernable event cost for renal transplant versus the annual cost of managing someone who has had a renal transplant. Thus, to estimate the steady-state cost for ESRD, it was necessary to also estimate the costs of renal transplantation. This was achieved by applying the event year cost of a transplant to the proportion of patients who had received a renal transplant during 1998 (transplant year) and combining that with the annual management cost applied to the proportion receiving a transplant during a previous year. The average annual costs of caring for a patient during the transplant year and in a subsequent year were obtained from the literature [46]. The average annual cost of treatment for hemodialysis and that for peritoneal dialysis were taken from a 1998 report published by the Agence d'évaluation des technologies et des modes d'intervention en santé (AÉTMIS) of Québec [47]. These costs were updated to year 2000 and "nationalized" according to the methodology described above.

The majority of the unit cost and resource use data used in this analysis were derived from Canadian sources. For rare exceptions pertaining to post-acute care, it was necessary to rely on resource use data from other sources. For example, no Canadian data were available for post-acute care following discharge from coronary artery bypass graft (CABG) or percutaneous transluminal coronary angioplasty (PTCA) readmissions in diabetic patients who had a previous AMI. Thus, it was necessary to employ diagnosis-specific disposition distributions for a similar population from five 1996/97 US all payer state databases to derive initial post-acute care patterns. The proportions were then adjusted to reflect the difference between Canadian and US case fatality rates for diabetic patients with AMI. Also, although initial discharge disposition data from Canada were used in the analysis, Canadian data detailing transitions to other levels of care over time for those with disabling strokes were not available; therefore 
Table 3: Typical event year costs (2000 CAN\$) by management phase for complications where hospitalization is, or may be, required.

\begin{tabular}{|c|c|c|c|}
\hline Complication & Hospital & Other Care* & Total Event Year \\
\hline \multicolumn{4}{|c|}{ All Patients Treated as Inpatients Initially } \\
\hline AMIT & $\$ 9,862$ & $\$ 8,773$ & $\$ 18,635$ \\
\hline Strokeף & $\$ 8,822$ & $\$ 24,434$ & $\$ 33,256$ \\
\hline TIA & $\$ 2,830$ & $\$ 432$ & $\$ 3,262$ \\
\hline LEA I & $\$ 15,996$ & $\$ 8,587$ & $\$ 24,583$ \\
\hline LEA 2 & $\$ 17,277$ & $\$ 8,800$ & $\$ 26,077$ \\
\hline \multicolumn{4}{|c|}{ Patients Treated as Either Inpatient or Outpatient Initially } \\
\hline Angina & $\$ 991$ & $\$ 2,192$ & $\$ 3,183$ \\
\hline Inpatient & $\$ 3,613$ & $\$ 6,048$ & $\$ 9,661$ \\
\hline Outpatient & $\$ 240$ & $\$ 1,032$ & $\$ 1,272$ \\
\hline DFU: & $\$ 1,957$ & $\$ 226$ & $\$ 2,183$ \\
\hline Inpatient & $\$ 6,475$ & $\$ 1,327$ & $\$ 7,802$ \\
\hline Outpatient & & $\$ 1,042$ & $\$ 1,042$ \\
\hline Hypoglycemia & $\$ 110$ & $\$ 1$ & $\$ 1 I I$ \\
\hline Inpatient & $\$ 4,142$ & $\$ 42$ & $\$ 4,184$ \\
\hline Outpatient & & $\$ 71$ & $\$ 71$ \\
\hline
\end{tabular}

$(A M I=$ acute myocardial infarction, DFU = diabetic foot ulcer, LEAI = first lower extremity amputation, LEA2 = second lower extremity amputation, TIA = transient ischemic attack) * Other Care includes all outpatient services for all patients. For those treated initially as inpatients, other care also includes sub-acute inpatient, home health and day care services where applicable. TIncludes pre-admission CPR/ambulance and hospital care.

we used our stroke economic model [48] to derive the state costs for stroke. The long-term transition data used in this model come from Sweden [49].

Only direct medical costs, those directly related to delivery of the health care service, are included in the estimates reported here. All event and state cost estimates are reported in 2000 Canadian dollars. Where 2000 values were not available, older estimates were inflated using the Health Care Inflation Index, a component of the Consumer Price Index, supplied by Statistics Canada [42].

\section{Results}

Table 2 displays the state and event costs for the complications. Table 3 provides a cost breakdown of the event year by management phases for those complications where all or some of the patients were treated initially as inpatients.

\section{Macrovascular Complications AMI}

It was assumed that all patients with an AMI were treated initially as inpatients. The acute care portion of the event cost is comprised of acute hospitalization $(\$ 9,739)$, including physician costs for the initial event and ambulance costs (\$237) for the 52\% [17] of patients requiring this type of transport to the hospital. Subsequent (postacute) care for AMI includes outpatient medical care, surgical follow-up care post-CABG, home health care, cardiac rehabilitation, long term facility care, and readmissions within the event year for a subsequent myocardia infarc- tion (MI), CABG, PTCA or coronary angiography. The subsequent care cost was developed by weighting the cost of these health care services by the proportion of patients using these services to derive the average cost per person. In other words, only those who had a CABG during their stay would have the surgical follow-up care included in their cost profile. The event year cost for AMI is $\$ 18,635$.

State costs of AMI were calculated to be $\$ 1,193$, per patient, per year on average. These include medications (i.e., aspirin, calcium antagonists, beta blockers, nitrates, angiotensin converting inhibitors, HMG-CoA reductase inhibitors) weighted by the proportion of patients using them, physician visits, and monitoring cardiology tests (i.e., electrocardiogram (ECG) and stress test). A small portion of diabetic patients who experienced an AMI (1.4 $\%)$ required long-term care facility placement according to OCCP data. The cost of this care is also reflected in the state cost. In addition to the sources listed previously, several additional publications were used to obtain information for the AMI resource use profiles [50-60].

Angina

On average, the event cost for angina is $\$ 3,183$, per person. This includes proportionately weighted estimates for several sub-groups: unstable angina, hospitalized $(\$ 9,661)$; angina treated in emergency room or on an urgent basis by a physician as an outpatient $(\$ 1,397)$; and an acute anginal episode treated by usual care physician $(\$ 1,230)$. In the absence of Canadian-specific data, the ratio of 3 stable to 1 unstable patient with angina [61], and 
the $96 \%$ proportion of unstable patients treated as inpatients were obtained from the literature [62]. OCCP data revealed that of those admitted with angina, $28 \%$ were transported by ambulance. Subsequent first year costs include the same cost centers as for AMI except that no patients became residents of a nursing home as a result. The medications included in the angina resource use profile include aspirin, calcium antagonists, beta blockers, nitrates, angiotensin converting inhibitors and statins. The costs for these drugs were weighted based on reported proportions of angina patients using them $[54,59,63]$.

State costs of angina were calculated to be $\$ 1,485$, per patient, per year on average. These included medications, physician visits, laboratory tests and monitoring cardiology tests (i.e., ECG and stress test). Additional resource use information regarding visits and tests was abstracted from published sources $[27,64,65]$.

\section{Ischemic Stroke}

The disabling consequences of stroke are reflected in the first year management costs, as more patients require continuing care services after discharge from the hospital. OCCP data and information from published literature [66-71] were used to determine post-acute care placement for rehabilitation, readmission for a subsequent stroke events and long term care in the first year. Acute care comprises only $27 \%(\$ 8,822)$ of the mean event cost for ischemic stroke $(\$ 33,256)$. This is half of the AMI proportion $(53 \%)$, highlighting the effect of increased need for post-acute care in stroke.

The mean annual state cost is $\$ 8,769$ and reflects outpatient monitoring, medications (i.e., aspirin) and the increased need for day care, durable medical equipment and permanent long-term care in this patient population.

\section{TIA}

It was assumed for this analysis that all patients diagnosed with a TIA who are diabetic would receive inpatient care initially. It was also assumed that all TIAs are truly transient - an assumption that finds some support in the OCCP TIA data where the only post-acute discharge dispositions were home (outpatient care), home health care and rehabilitation. Thus, no health care services associated with permanent residual disability (e.g., long term care placement) were considered for inclusion in the cost estimate. Additional resource use data were obtained from Nova Scotia [72]. The mean event cost for TIA is $\$ 3,262$. Aspirin is the only medication included in the cost profiles for TIA. Thus, the mean state cost of $\$ 73$ for TIA is based on monitoring visits to a physician and daily aspirin.

\section{Microvascular Complications Nephropathy}

The costs for microalbuminuria and gross proteinuria are based primarily on recommendations from Canadian clinical practice guidelines and consist only of laboratory tests on urine and physician visits. The use of ACE Inhibitors is discussed in the literature with regard to the prevention of progression of renal disease. The Canadian clinical practice recommendations of 1998 recognize that some patients with type 2 diabetes who have proteinuria may benefit from this type of therapy [27] and suggest that ACE Inhibitors should be considered, but do not recommend them for all patients. As no data are available pertaining to the proportion of patients on this type of therapy solely for the purpose of preventing further renal deterioration, the cost is not included in the current estimate. The event cost for microalbuminuria is $\$ 62 ; \$ 54$ for gross proteinuria. The state costs are $\$ 10$ and $\$ 18$ for microalbuminuria and gross proteinuria, respectively.

The annual cost $(\$ 63,045)$ of caring for a patient with ESRD represents a weighted average of the annual costs for hemodialysis, peritoneal dialysis, and renal transplant.

\section{Retinopathy}

The costs for macular edema and proliferative retinopathy are comprised of physician visits, ophthalmology consults, and the use of diagnostic and therapeutic eye procedures (i.e., color fundus photography, fluorescein angiography and photocoagulation). Published Canadian clinical practice guidelines for diabetic retinopathy were the source for resource use $[27,28]$. The mean event costs for these complications are $\$ 423$ for macular edema and $\$ 379$ for proliferative retinopathy, respectively when photocoagulation is used. If both conditions are present in one patient, the event cost rises to $\$ 495$. The state cost of $\$ 40$, comprised of additional monitoring by an ophthalmologist, is the same for both conditions.

Blindness does not have an event cost, as there is no event per se. Rather, the decent into blindness due to diabetes is the result of either failure to detect or failure to treat retinopathy at an earlier stage. Unfortunately, there has been little information developed on the annual cost of blindness, let alone the annual direct medical cost in any country. No information could be found from the literature, government agencies or relevant private agencies that deal with the blind. One of the only available sources for direct medical costs is a published US-based cost from 1990 [73]. By converting this figure to Canadian dollars using the 1990 exchange rate of $\$ 0.8572$ and then inflating the Canadian value to a 2000 Canadian dollar values a state cost of $\$ 2,111$ for blindness was estimated. 


\section{Neuropathy}

Three levels of neuropathy were examined in this analysis: symptomatic neuropathy, and first and second LEA. The resource use for symptomatic neuropathy was limited to diagnosis and monitoring, as there is no specific treatment for this condition, and use of the palliative options available is not consistent. Thus, this is likely an underestimation of the cost for this complication. Published clinical practice guidelines were used to establish the event year resource use profile $[27,28,74]$. The event year cost is $\$ 148$ per person. There is no state cost as beyond the initial diagnostic tests, there is no further management recommended.

Neuropathy and foot ulcers can lead to amputations. These can occur at various levels: toe, foot, below the knee and above the knee. Thus, the cost for each type of amputation was calculated using OCCP data and then weighted by the proportion of diabetic patients having that type of surgery to determine the overall event cost for a LEA. Furthermore, it has been reported that $50 \%$ of patients with diabetes who have a LEA will go on to have a second LEA within 5 years [75]; therefore, event costs for a first and second amputation were calculated separately. As it is not possible to discern first versus second LEA in a claims database, proportions by type of amputation were used to differentiate between first and second amputation inpatient costs. No Canadian data were available to make this differentiation possible at all of the necessary levels required for this analysis; therefore, a US based study from Rochester, MN was used to provide proportions of amputation type for first and second LEA [76]. The cost of an above the knee amputation (AKA) is considerably more than that of a toe amputation, not just in the hospital $(\$ 19,760$ versus $\$ 6,460)$ but also beyond due to the significantly higher level of disability resulting from an AKA. Information regarding post-acute care dispositions, rehabilitation, readmissions for debridement and major stump revisions, and use of prosthetic devises and durable medical equipment were obtained from the OCCP database, provider surveys and publications [77-79]. The increase in event cost from first $(\$ 24,583)$ to second $(\$ 26,077)$ represents a shift to a higher anatomical, and thus, more costly level of amputation for the second amputation as noted in the Rochester study [76].

LEA can be a very disabling event for a patient and has consequences beyond the event year. No published information was identified that could isolate ongoing annual direct management costs related to LEA versus usual management of a patient with diabetes, thus, only costs directly related to the LEA (i.e., long-term facility residential care and the management, refitting of the prosthetic device) are included in the state cost for LEA. The state cost for LEA 1 is $\$ 1,020$. To avoid double-counting, given the cost components of the LEA state profile, the state cost of the second LEA is conservatively assumed to be zero as it was not possible to discern which prosthesis related costs would be specific to the second prosthesis versus costs already included in the state cost for LEA1[77,80-82].

\section{Diabetic Foot Ulcer}

For the purpose of this analysis, foot ulcers are defined as those that heal without amputation or vascular surgery. Since not all diabetic foot ulcers are treated in an inpatient setting, the event cost is a weighted average of inpatient $(\$ 7,802)$ and outpatient care costs $(\$ 1,042)$. OCCP data and information from the literature were used to determine proportions and resource use [21,83-85]. The event cost for diabetic foot ulcer is $\$ 2,183$ per person, on average. There is no state cost calculated for this complication as it is considered to be episodic.

\section{Hypoglycemia}

For the purpose of this analysis, only hypoglycemic events that generate the use of medication or formal health care services (formal care) were included. Three levels of resource use were considered for this condition: the lowest level of formal care is self-treatment with a glucagon injection and no intervention from medical personnel (\$24); the middle level is an ambulatory care or emergency room consultation (\$194); the highest level is hospitalization with a follow-up physician visit $(\$ 4,184)$. A cost was developed for each level. An overall hypoglycemic event cost was derived by applying the appropriate weights, taken from US studies, as no Canadian data were available $[86,87]$. Only $1 \%$ of those experiencing a hypoglycemic event are assigned inpatient costs. The event cost for this episodic complication is \$111.

\section{Discussion}

Diabetes and its complications are major health care problems for Canada. Nearly $6 \%$ of the Canadian population is affected and First Nations have one of the highest reported prevalences (26\%) in an indigenous population [88]. It has been recognized that health care expenditures related to the complications of diabetes account for a substantial proportion of the public health care budget [89] and that related costs are likely to escalate as the population ages. Yet, given the size of the problem, the acknowledged concern and initiatives undertaken to address diabetes on a national level and for the native Canadian population in particular, it is surprising that there is so little available Canadian information about the cost of the complications of diabetes, particularly at a level detailed enough to be meaningful to decision makers or those doing economic analyses. The purpose of this paper is to provide comprehensive cost estimates for several common complications of diabetes in a manner that can be useful to interested parties. 
A main goal of this analysis was to develop Canadian-specific cost estimates using Canadian unit cost and resource use information wherever possible. This point is stressed as the importance of using country-specific data in an economic analysis cannot be ignored. As noted earlier, it is not uncommon to find US or European costs for diabetes used as a proxy for Canadian costs, even in official reports [6]; however, the true relevance of these costs to a Canadian population can only be assumed. In previously published work [12], we have shown that the use of US data, even when Canadian unit costs are used can lead to inaccurate, albeit well-intentioned estimates. In that example, a difference of approximately $\$ 1,400$ dollars in the state cost for stroke was noted when US resource use data were replaced with Canadian data. As the state cost is applied to every year the patient is in that health state, a substantial miscalculation of the lifetime cost attributed to stroke would have been produced, even though it would have been based on the best available data and accepted as a reasonable proxy in the absence of Canadian data.

Although there may be clinical consensus on the management of a condition, type and availability of health care services, medical practice patterns, and access to care will affect the type and level of care actually delivered. Thus, differences beyond those relating to just monetary conditions must be acknowledged when using proxy data, as sometimes their use is unavoidable. While every effort was made to use only Canadian-based data in this analysis, it was not possible in some cases (e.g., aspects of LEA and of AMI). Does that mean that those estimates relying on some data from elsewhere should be ignored? We would argue "no" even in the face of the cautionary words provided above. All unit costs used in this analysis are from Canadian sources and the vast majority of resource use data are also Canadian. The estimates provided here are the closest reflection possible of the costs for these complications in Canada given the data available at the time of the analysis. They can and should be used, but with an understanding that for the few estimates where proxy data have been employed, the cost may not be a precise estimate for Canada.

Apart from the use of proxy data, some of the complication costs may be overestimated or underestimated due to the content of the resource use profile. For example, the TIA estimate may be an overestimation of the event cost if a substantial number of such patients are not treated in the hospital initially in Canada. If the TIA profile were to include a large proportion of patients treated initially as outpatients, the event cost for TIA could be decreased by as much as $45 \%[16,90]$. It is likely that the foot ulcer, LEA and symptomatic neuropathy estimates are underestimated as data for some potentially relevant cost components were not available. The degree of uncertainty in these esti- mates cannot be quantified because in most cases the source data do not provide it and there are reasons other than statistical imprecision that may also contribute.

The use of administrative databases, as in this analysis, brings with it concern regarding the accuracy of ICD-9 coding. Published coding error rates relating to diabetes in Canada could not be identified. While a study from the U.K. in the early 1990s showed that there was under-coding of diabetes in hospital records [91], later studies from the US have reported a greater than $90 \%$ accuracy rate in coding of major macrovascular complications in diabetic patients [92]. The coding error rate in the OCCP data is unknown, but for the purpose of this analysis, it is only of concern if there is a cost-relevant bias in the cases included. It is unclear whether such a bias exists. Ideal circumstances would allow for the development of cost estimates based on a comprehensive study, designed not to influence resource use, of unselected patients with sufficient follow-up. Unfortunately, that ideal rarely exists. This cost estimate created by assembling existing Canadian data provides health care decision makers in Canada, who cannot wait for the ideal data to accumulate, key information heretofore unavailable.

\section{Conclusion}

While health care promotion and education are valuable tools in the fight against diabetes, the condition and its complications will continue to have a profound impact on the health of Canadians, as well as provincial and national health care budgets for the foreseeable future. New treatments are being developed to improve glycemic control in those with diabetes with the goal of preventing or delaying some of the devastating complications associated with the disease. While appropriate medical care of the patient should be the prevailing factor for all health care decision makers, whether at the care delivery or the policy level, economic factors cannot be ignored. In order to determine which therapeutic agents are appropriate for use, cost-effectiveness, as well as efficacy and safety should be weighed. The estimates in this analysis do not provide cost-effectiveness information for any type of treatment for diabetes, but we believe that they do provide valuable cost inputs for any researcher or policy maker who needs such information to carry out an economic analysis.

\section{Abbreviations}

AÉTMIS - Agence d'évaluation des technologies et des modes d'intervention en santé

AKA - above the knee amputation

AMI - acute myocardial infarction

CABG - coronary artery bypass graft 
CMGs - case mix groupings

ECG - electrocardiogram

ESRD - end-stage renal disease

ICD-9 - International Classification of Diseases

LEAs - lower extremity amputations

LOS - length of stay

ME - macular edema

MI - myocardia infarction

OCCP - Ontario Case Cost Project

PTCA - percutaneous transluminal coronary angioplasty

TIA - transient ischemic attacks

US - United States

US\$ - United States dollars

\section{References}

I. Health Canada Health Canada information backgrounder: $\mathrm{Ca}$ nadian Diabetes Strategy [http://www.hc-sc.gc.ca/english/archives/releases/1999/99135ebk3.htm] February 18, 200 I

2. Health Canada Diabetes in Canada: Facts and Figures [http:// www.hc-sc.gc.ca/hppb/ahi/english/resources/index.html] February I8, 2001

3. Tan J $\mathrm{J}$ and MacLean DR Epidemiology of diabetes mellitus in Canada Clin Invest Med 1995, 13:240-246

4. UK Prospective Diabetes Study Group Intensive blood-glucose control with sulfonylureas or insulin compared with conventional treatment and risk of complications in patients with type 2 diabetes (UDPDS 33) Lancet 1998, 352:837-853

5. Ur E Macrovascular disease in diabetes. Pathophysiology and management Canadian Diabetes 1998, I I(2):2-8

6. Canadian Diabetes Advisory Board Diabetes in Canada: strategies toward 2000 Canadian Diabetes Association 2000, [http:// www.hc-sc.gc.ca/pphb-dgspsp/pubssub e.html]

7. Health Canada Diabetes in Canada, 1999 [http://www.hc-sc.gc.ca/ $\mathrm{hpb} / \mathrm{lcdc} /$ publicat/diabet $99 . \mathrm{html}]$ July 20, 2000

8. Canadian Institute for Health Information Canadian organ replacement registry report $200 \mathrm{I}$ Dialysis and renal transplantation. Ottawa 200I,

9. Health Canada National Diabetes Surveillance System 200I2002 Business Plan [http://www.hc-sc.gc.ca/hppb/ahi/diabetes/english/index.html] October 16, 200I

10. Canadian Opthalmological Society Diabetes and the Eye. 1997 [http://www.eyesite.ca/english/public-information/eye-conditions/diabetes-and-the-eye.htm] July 19, 2000

11. Health Canada, Laboratory Centre for Disease Control Economic burden of illnesses in Canada Catalogue No. 1993 H2I_136I 1993E. Ottawa 1997,

12. O'Brien JA, Caro I and Getsios D Diabetes in Canada: Direct medical costs of major macrovascular complications Value Health 200I, 4(3):258-265

13. Eastman RC, Javitt JC and Herman WH Model of Complications of NIDDM. II. Analysis of the health benefits and cost-effectiveness of treating NIDDM with the goal of normo-glycemia Diabetes Care 1997, 20:735-744
14. Eastman RC, Javitt JC and Herman WH Model of Complications of NIDDM. I. Model construction and assumptions Diabetes Care 1997, 20:725-734

15. Caro J], Klittich WS and Raggio G Economic Assessment of Troglitazone as an Adjunct to Sulfonylurea Therapy in the Treatment of Type 2 Diabetes Clin Ther 2000, 22: I 16-127

16. O'Brien JA, Shomphe LA and Kavanagh PL Direct Medical Costs of Complications Resulting from Type 2 Diabetes in the U.S Diabetes Care 1998, 2 I (7): I I22-I I 28

17. The Ontario Case Cost Project The Ontario Case Cost Program Database 1994, 95

18. The Ontario Case Cost Project Ontario Case Cost Program Database 1995-96

19. St. Anthony's ICD-9-CM Code Book (Edited by: Reston VA) St. Anthony Publishing Inc. 1996,

20. FY 1995/96- Typical Cases file Available from OCCP website [http:/ /www.occp.com] April 200I

21. Health Resourcing Branch Health Costing in Alberta, 1999 Annual Report Alberta Health and Wellness, 1999 Available from Alberta Health website [http://www.health.gov.ab.ca/public/document/ ar99-00/] February 18, 200I

22. Heart and Stroke Foundation of Canada Heart Disease and Stroke in Canada Ottawa: Heart and Stroke Foundation of Canada 1995

23. Heart and Stroke Foundation of Canada Heart Disease and Stroke in Canada Ottawa: Heart and Stroke Foundation of Canada 1997

24. Health Canada Statistical Report on the Health of Canadians. Ottawa: Health Canada, 1999 [http://www.statcan.ca/english/ freepub/82-570-XIE/free.htm] May 14, 2000

25. Diabetes Division, Bureau for Cardio-Respiratory Diseases and Diabetes Health Canada. Diabetes in Canada. National Statistics and Opportunities for Improved Surveillance, Prevention, and Control Minister of Public Works and Government Services, Canada 1999 ,

26. Fallen EL, Armstrong P and Cairns J Report of the Canadian Cardiovascular Society's Consensus Conference on the Management of the Postmyocardial Infarction Patient Can Med Assoc J I99|, I44(8): I015-1025

27. Meltzer S, Leiter $L$ and Daneman D 1998 clinical practice guidelines for the management of diabetes in Canada Can Med Assoc J 1998, I 59(8 Suppl):SI-S29

28. Harris SB, Meltzer S], Zinman B and on behalf of the Steering Committee for the Revision of the Clinical Practice Guidelines for the Management of Diabetes in Canada New guidelines for the management of diabetes: a physician's guide Can Med Assoc J 1998, I 59:973-978

29. 2000 Report Dialysis and Renal Transplantation, Canadian Organ Replacement Register, Canadian Institute for Health Information, Ottawa, Ontario, June I:June 2000

30. Jacobs P, Shanan M and Roos NP Cost List for Manitoba Health Service. Manitoba Centre for Health Policy and Evaluation, Department of Community Health Services, University of Manitoba January, 1999

3I. Institute of Health Economics A National List of Provincial Costs for Health Care: Canada $1997 / 98$ [http://www.ihe.ab.ca] March 2001

32. Ontario Ministry of Health Diabetes: Strategies for Prevention Report of the Chief Medical Officer of Health. Toronto: Ontario Ministry of Health and Long-term Care, 1999 [http:// www.gov.on.ca/MOH] June 3, 2000

33. Long-term Care in Saskatchewan, Final Report No. 2. Saskatoon: Health Services Utilization and Research Commission 1994

34. Alcock D, Danbrook $C$ and Walker D Home care clients, providers and costs Can J Public Health 1998, 89(5):297-300

35. Ellencweig AY, Stark AJ and Pagliccia N The effect of admission to long-term care program on utilization of health services by the elderly in British Columbia Eur J Epidemiol 1990, 4(2): 175-83

36. Friedman $\mathrm{R}$ and Kalant $\mathrm{N}$ Comparison of long-term care in an acute care institution and in a long-term care institution Can Med Assoc J 1998, I59(9): I I07-I I I 3

37. Manton KG, Cornelius ES and Woodbury MA Nursing home residents: a multivariate analysis of their medical, behavioral, psychosocial, and service use characteristics / Gerontol 1995, 50A(5):M242-M25 I 
38. Stark $A$ J and Gutman GM Client transfers in long-term care: five years' experience Am J Public Health 1986, 76:1312-1316

39. Ontario Ministry of Health and Long-Term Care Ontario Physician Fee Manual, July, 2000 [http://www.gov.on.ca/MOH] January 200 I

40. Ontario Ministry of Health and Long-Term Care Ontario Laboratory Fees, April, 1999 [http://www.gov.on.ca/MOH] January 200I

41. Ontario Ministry of Health Ontario Drug Benefit Formulary Comparative Drug Index. No. 37, 2001 [http:// www.health.gov.on.ca/english/providers/program/drugs/formulary/ ed38 0 bk.pdf] February 200

42. Statistics Canada [http://www.statcan.ca/] March 2000

43. 2000 Report Dialysis and Renal Transplantation, Canadian Organ Replacement Register, Canadian Institute for Health Information, Ottawa, Ontario I:June 2000

44. "Transplant Statistics." [http://secure.cihi.ca/cihiweb/] June 2000

45. Canadian Organ Replacement Register (CORR) Renal Replacement Statistics: August 2000 [http://secure.cihi.ca/cihiweb/] February 20,2001

46. Laupacis $A$, Keown $P$ and Pus N A study of the quality of life and cost-utility of renal transplantation Kidney Int 1996, 50(I):235242

47. Rapport CÉTS 98-3 RF Hémodialyse et dialyse péritonéale: analyse comparative des rapports coût-efficacité Montréal: CETS 1998, xi-37

48. Caro JJ, O'Brien JA and Klittich WS The economic impact of Warfarin prophylaxis in non-valvular atrial fibrillation Journal of Disease Management and Clinical Outcomes 1997, I(2):54-60

49. Thorngren $M$ and Westling $B$ Rehabilitation and achieved health quality after stroke. A population-based study of $\mathbf{2 5 8}$ hospitalized cases followed for one year Acta Neurol Scand 1990, 84:374-380

50. Anderson HV, Gibson RS and Stone PH Management of unstable angina pectoris and Non-Q-Wave acute myocardial infarction in the United States and Canada (The TIMI III Registry) Am J Cardiol 1997, 79: 144I-1446

51. Pilote $L$, Racine $N$ and Hlatky $M$ Differences in the treatment of myocardial infarction in the United States and Canada Arch Intern Med 1994, 154:1090-1096

52. Senaratne MPJ, Irwin ME and Shaben S Feasibility of direct discharge from the coronary/intermediate care unit after acute myocardial infarction J Am Coll Cardiol 1999, 33:1040-1046

53. Tu JV, Naylor D and Austin P Temporal changes in the outcomes of acute myocardial infarction in Ontario, 1992-1996 Can Med Assoc J 1999, 16 I (10): |257-1261

54. Medical Management of Ischemic Heart Disease: the Optimal Use of Nitrates. University of British Columbia Therapeutics Letter, 1995; Issue 6 [http://www.ti.ubc.ca] June 2000

55. Fallen EL Acute and post-myocardial infarction In: Therapeutic Choices (Edited by: Gray J) Ottawa: Canadian Pharmaceutical Association 1995 ,

56. Riviére $M, W$ ang $S$ and Leclerc $C$ Cost-effectiveness of simvastatin in the secondary prevention of coronary artery disease in Canada Can Med Assoc ] 1997, I 56(7):991-997

57. Rouleau JL, Moyé LA and Pfeffer MA A comparison of management patterns after acute myocardial infarction in Canada and the United States N Engl J Med 1993, 328:779-784

58. Mark DB, Naylor CD and Hlatky MA Use of medical resources and quality of life after acute myocardial infarction in Canada and the United States N Engl | Med I994, 33 I: I I 30- I I 35

59. Yusuf $S$, Flather $M$ and Pogue J Variations between countries in invasive cardiac procedures and outcomes in patients with suspected unstable angina or myocardial infarction without initial ST elevation Lancet 1998, 352:507-5।4

60. Dafoe $W$ and Huston $P$ Current trends in cardiac rehabilitation Can Med Assoc J 1997, I 56(4):527-532

61. Mark D, Lam L and Lee K Effects of coronary angioplasty, coronary bypass surgery, and medical therapy on employment in patients with coronary artery disease: a prospective comparison study Ann Intern Med 1994, I 20(2): I I I- I I 7

62. Katz D, Griffith J and Beshansky J The use of empiric clinical data in the evaluation of practice guidelines for unstable angina JAMA 1996, 276(19): I568-1574

63. Health Canada, I998 FASTRAK II data from The Changing Face of Heart Disease and Stroke in Canada, 2000 [http:/l www.hc-sc.gc.ca] March 2001
64. Gray J and ed Therapeutic Choices Ottawa: Canadian Pharmaceutical Association 1995,

65. Braunwald E, Mark DB and Jones RH Unstable Angina: Diagnosis and Management. Clinical Practice Guideline Number 10 (amended) AHCPR Publication No. 9400602. Rockville, MD: Agency for Health Care Policy and Research and the National Heart, Lung and Blood Institute, Public Health Service, U.S. department of Health and Human Services May, 1994

66. Mayo NE, Wood-Dauphinee S and Gayton D Nonmedical beddays for stroke patients admitted to acute-care hospitals in Montreal, Canada Stroke 1997, 28:543-549

67. Brosseau L, Phillippe P and Potvin L Post-stroke inpatient rehabilitation. I. Predicting length of stay Am J Phys Med Rehabil 1996, 75(6):422-430

68. Brosseau L, Potvin $L$ and Phillipe $P$ Post-stroke inpatient rehabilitation. II. Predicting discharge disposition Am J Phys Rehabil 1996, 75(6):43I-436

69. Mayo NE, Hendlisz J and Goldberg MS Destination of Stroke Patients Discharged from the Montreal Area Acute-Care Hospitals Stroke 1989, 35I-356

70. Mayo NE, Wood-Dauphine $\mathrm{S}$ and Ahmed S Disablement following stroke Disabil Rehabil 1999, 2 I(5/6):258-268

7I. Smurawaska LT, Aleandrov AV and Bladin CF Cost of Acute Stroke in Toronto, Canada Stroke 1994, 25(8): |628-163|

72. Gubitz $G$, Phillips $S$ and Dwyer $\vee$ What is the cost of admitting patients with transient ischemic attacks to hospital? Cerebrovasc Dis 1999, 9:210-214

73. Chiang $\mathrm{Y}$, Bassi LJ and Javitt JC Federal budgetary cost of blindness Millbank Q 1992, 70:319-340

74. American Diabetes Association Diabetic neuropathy (Position Statement) Diabetes Care 1996, I9(Suppl I):S67-S7 I

75. Reiber G Epidemiology of the diabetic foot In The Diabetic Foot (Edited by: Levin M, O'Neal L, Bowker J) Boston, MA, Mosby Year Book 1993,

76. Humphrey LL, Palumbo PJ and Butters MA The contribution of non-insulin dependent diabetes to lower-extremity amputation in the community Arch Intern Med 1994, I 54:885-892

77. Lexier RR, Harrington IJ and Woods JM Lower Extremity Amputations: a 5-Year Review and Comparative Study Can J Surg 1987, 30(5):374-376

78. Alberta Physiotherapy Association [http://www.albertaphysio.org] April 2001

79. Régie de L'assurance Maladie du Québec Manuel du programme d'appareils suppléant à une déficience physique Mai 2000

80. Levin ME and O'Neal LW The Diabetic Foot: Pathophysiology, Evaluation and Treatment St Louis, MO CV Mosby 1988,

81. Polhjolainen T, Alaranta $\mathrm{H}$ and Wikstrom J Primary survival and prosthetic fitting of lower limb amputees Prosthe Orthot Int 1989, 13:63-69

82. Moore TJ, Barron J and Hutchinson F Prosthetic usage following major lower extremity amputation Clin Orthop 1989, 238:219. 224

83. Reiber GE Who is at risk of limb loss and what to do about it? J Rehab Res Dev 1994, 3 I:357-362

84. Ramsey SD Incidence, Outcomes and Cost of Foot Ulcers in Patients with Diabetes Diabetes Care 1999, 22(3):382-387

85. Olin JW Medical costs of treating venous stasis ulcers: evidence from a retrospective study Vasc Med 1999, 4(I): I-7

86. Abraira C, Colwell JA and Nuttall FQ Veterans Affairs Cooperative Study on glycemic control and complications in type II diabetes Diabetes Care 1995, 18: I I I3-I I 23

87. Diabetes Control and Complications Trial research Group Adverse events and their association with treatment regimens in the Diabetes Control and Complications Trial Diabetes Care 1995 18:1415-1427

88. Harris SB, Gittelson J and Hanley A The prevalence of NIDDM and associated risk factors in native Canadians Diabetes Care 1997, 20(1):185-187

89. Diabetes Research and Treatment Center Diabetes - A Major Public Health Problem Available from the University of Manitoba's website [http://www.umanitoba.ca/outreach/drtc] March 2000

90. O'Brien JA, Patrick AR and Caro J Estimates of Direct Medical Cost for Microvascular and Macrovascular Complications Resulting from Type 2 Diabetes Mellitus in the United States in $\mathbf{2 0 0 0}$ Clinical Therapeutics 2003 
91. Leslie PJ, Patrick AW and Hepburn DA Hospital in-patient statistics underestimate the morbidity associated with diabetes mellitus Diabet Med 1992, 9(4):379-385

92. Newton KM, Wagner EH and Ramsey SD The use of automated data to identify complications and comorbidities of diabetes: a validation study J Clin Epidemiol 1999, 52(3): 199-207

\section{Pre-publication history}

The pre-publication history for this paper can be accessed here:

http://www.biomedcentral.com/1472-6963/3/7/prepub

Publish with Bio Med Central and every scientist can read your work free of charge

"BioMed Central will be the most significant development for disseminating the results of biomedical research in our lifetime. "

Sir Paul Nurse, Cancer Research UK

Your research papers will be:

- available free of charge to the entire biomedical community

- peer reviewed and published immediately upon acceptance

- cited in PubMed and archived on PubMed Central

- yours - you keep the copyright

Submit your manuscript here:

http://www.biomedcentral.com/info/publishing_adv.asp 